\title{
Development of skills in children with ASD using a robotic platform
}

\author{
Sara Silva (a52566@alunos.uminho.pt) ${ }^{1}$, Filomena Soares ${ }^{1}$, Sandra $\operatorname{Costa}^{1}$, Ana Paula Pereira ${ }^{2}$, Fátima Moreira ${ }^{3}$ \\ ${ }^{1}$ R\&D Centre Algoritmi, University of Minho, Campus of Azurém, Guimarães, Portugal \\ ${ }^{2}$ R\&D Centre of Education CIED, University of Minho, Campus of Gualtar, Braga, Portugal \\ ${ }^{3}$ APPACDM, Braga, Portugal
}

\begin{abstract}
The interaction and communication skills are essential to live in society. However, individuals with autism spectrum disorders (ASD) have a gap in these abilities which affects their daily life. Previous studies suggest that children with ASD demonstrate some positive behaviors in presence of a robotic platform. This study intends to evaluate the effect of a robotic platform on children with ASD, checking if the platform can be a stimulating agent for children's interaction, as well as a skill learning promoter. So, it is used the robot Lego Mindstorms NXT as a mediator/reward to encourage children with ASD to interact with others and also to learn some cognitive skills.
\end{abstract}

Index Terms-Autism Spectrum Disorders; Lego Mindstorms NXT, Assistive Robotics.

\section{CONTEXT}

Autism spectrum disorders (ASD) are characterized by a development deficit in several areas, including impairments in social, communication and cognitive skills and stereotyped patterns behaviors, interests and activities [1, 2]. Individuals with ASD have common characteristics which the National Autistic Society brings together in three different groups designated by triad of impairments, which included 1) qualitative changes in social interactions, 2) qualitative changes in verbal and non verbal communication skills, and 3) a reduced, repetitive and stereotypical repertoire for activities and interests [3-5]. Thus, they have resistance to changes in their routines; tend to seek stable environments and have a fixation on mechanical objects that have movement $[1,3,5]$.

Although there is no cure for the disorder, there are currently multiple intervention methods that attempt to improve the quality of life and skills of the individuals with ASD, either at a cognitive level, or at social interactions and speech skills as well.

The TEACCH (Treatment and Education of Autistic and Related Communications Handicapped Children) model aims to a more autonomous daily life for individuals with ASD. The main role of this model is to provide support to individuals with ASD and their families. The principles of TEACCH are based on the ideas of: a) trying to create further adaptation at home, including the parents in interventions and sharing activities; b) the elaboration of an individual intervention program that allows a personalized evaluation and intervention; c) and structuring the teaching environments, with exposition of the routines in frames, agendas or walls. This method turns the environment into an easier context to understand for individuals with ASD [2].
Other method of intervention is the ABA (Applied Behavior Analysis) model that consists in the intervention with application of behavioral analysis methods which attempt to correct the actions. The core idea of this model is to make an early intervention promoting the individuals' development, encouraging their autonomy. Each skill is taught individually and, then, the correct answer to the instruction is positively reinforced - the reward [6].

The PECS (Picture Exchange Communication System) model attempts to teach the individuals with ASD to start activities through the use of figures, and to persist on communication until the peer answer. This model appears as an alternative to verbal communication and arranges an evident and detailed manual of treatment, which allows organizing the process of teaching [7].

Another approach is the Floortime model that intends to involve the individual with ASD in affective relationships. For periods of time (20-30 minutes), parents and caregivers go to the floor, as well as the children. The goal is to allow the development of spontaneous interactions in a wider space than a table [8]. In this model, activities are designed to enable the reciprocal communication, sensorial perception, motors skills, broadening the repertoire of interactive activities, and trying to develop the skills related to emotions [9].

Interactive robotic platforms have been used as mediators in the intervention with children with ASD [10-13]. Autonomous robots have different functionalities to interact with children with ASD, for example music, color, visual effects or mechanical movements. Some examples of projects in this field are AuRoRa project, Keepon project and IROMEC project.

One of the pioneers projects in robotic-autism area is AuRoRa (Autonomous Robotic Platform as a Remedial tool for Children with Autism). Since 1998 this project has the objective to investigate the effects of robot, used as a tool, to engage children with ASD in several tasks, allowing the development of social interactions, mainly eye contact, joint attention, imitation games, and others. This project uses different robots, but the latest work refers to KASPAR [11].

KASPAR (Kinesics And Synchronization in Personal Assistant Robotics) is a humanoid robot able to express emotions with less complexity than a human face [10]. It allows expressing some basics emotional states, such as happiness, neutral, sadness and surprising [11]. These abilities 
have helped children with ASD focus in the KASPAR face without showing either anxiety or feelings overload, which happen more often when interacting with humans [10].

KEEPON [12] is capable of expressing attention (eye direction) and emotions (pleasure and excitement) interacting with children with its simple look and uncomplicated actions. Because KEEPON changes from eye contact to focusing on an object, it can react emotionally every time children do a significant social interaction. When the child looks or points to the same object that KEEPON is focusing on, it can jump and swing to show its enthusiasm; such reaction can encourage the child to keep on interacting [10].

IROMEC (Interactive Robotic Social Mediators as Companions) project started in 2006 and investigates the design and the role of autonomous and interactive robotic objects on interventions and educational contexts in children with special needs [13]. This project aims to develop a robotic toy for children with cognitive impairments. Thus, it is investigated the way how robots can be used as social mediators, encouraging children with disabilities to achieve a range of games styles, from solitary to cooperative games, including peers, parents and caregivers [10].

Other project developed at University of Minho (UM) is Robótica-Autismo (www.robotica-autismo.com). It intends to apply a robotic platform for improving the social life of individuals with cognitive disabilities, ASD and mental impairments. In this study, they use the Lego Mindstorms NXT robot as a mediator to improve the skills of interaction and communication with the environment and with others. The work was developed in five phases and the main task involved the request of a ball to the robot by the children, through of simple words. At the end, it was possible to observe that the children played and interacted with others and said simple words [4].

The work described in this paper considers a wider sample with children from six until sixteen years old, where the experimental sessions were performed in different environments and contexts.

\section{GOALS}

This work intends to introduce a robotic platform in the intervention's methodology in children with ASD, analyzing the effects produced by a robot on their social behaviors. Thus, this work attempts to enable children with ASD to become more autonomous and dynamic, improving their skills of interaction and communication, as well as to promote the learning of further social and academic abilities, to attract the attention and to establish contact with children with ASD. At the end of the work, we should have some questions answered, such as: "Can the robot enable the interactions of children with ASD?" or "Can the robot maintain the focus of children with ASD in a way that favors the learning of skills?" Below it is described the implemented methodology to answer these questions.

\section{IMPLEMENTATION}

The first part of this work was dedicated to establishing partnerships with some schools in the north of Portugal. The partnership with these schools is fundamental because we have the support of the professionals responsible for the children with ASD, helping the design and development of experiments.

\section{A. Robot}

Most studies present expensive robots, and in some cases, they are not commercially available. A convenient alternative platform is the Lego Mindstorms NXT robot (www.lego.com). These robots are available on the market since 2006; they are oriented to education, with a wide range of sensors, with memory and processing capacity. This robot is simple but modular; it is easily programmed and may present different forms. Hence, this robotic platform gathers a set of features that allows its use in the experiments undertaken in this work, such as it has an interesting-good price tool, its movements and visible mechanical parts allow to draw the attention and to establish contact with children with ASD.

\section{B. Activities}

The experiments consisted of 12 sessions of 10 minutes each in a classroom of the school, where the activities took place. At the moment, six of the twelve sessions were already performed (Tasks 1, 2 and 3 referred below). The preliminary results of this work are discussed in Section V. In the near future the remaining sessions (Tasks 4 and 5) will be completed.

Inside each room, cameras were set up so that each experiment was recorded on video. The cameras were placed in order to obtain the most information about the child during the experiment. Thus, the main camera was placed to capture the face of the child to see where he/she was looking at; the second camera was placed to record the entire experiment; and a third camera was adjusted to follow the movements performed by the child's lower members. The elements which constituted the experiment were: the researcher and the child, the robot, a rail, different colored balls (two blue balls, two red and an orange one), a bag where the balls were placed and colorful cards. The proceeding of the activities was bidirectional and implied the trade of balls between the child with ASD and the researcher, who was always in front of the child, at the other end of the table.

The success criteria were measured by the number of times that the children with ASD performed the task when he/she was asked. This way, they were defined four success criteria: in the first one, the child must perform the task one out of five times; in the second success criteria the child must perform the task two out of five times; in the third success criteria the child must perform the task four out of five times; in the fourth success criteria the child must perform the task five out of five times.

The methodology was split into five different phases, during two months: 1) Task definition - At the beginning of the study, a meeting took place between researchers, psychologists and professionals, to facilitate the definition of the study strategies and methodologies to apply during the experiments. Next, each child was analyzed, to adjust the activity to the skills that were needed to develop in each case. A questionnaire was delivered to parents and caregivers, with the purpose of getting to know the skills of the selected children; 2) Pre-test - 
In this stage, the first contact between researcher and child took place, as well as the contact between the child and the robot. The experiment lasted for ten minutes, in which intervened the child with ASD and the researcher. The robot worked as a positive reinforcement to perform the task; 3) Practice - After the first contact, we introduced the activity in the individual work routine of the child with ASD, twice a week, for three weeks, in ten minutes sessions; 4) Re-test - Evaluation of the consistency of learning. Once the absolute success criteria are reached, i.e., five successes out of five times the task is performed, the experiment stops for a week. With this settled, it is performed one session (re-test). This session is developed in the same parameters of the previous sessions; 5) Generalization - Evaluation of the skill generalization. In the sessions following the re-test, the robot is removed and it is observed the generalization ability of the child. Initially, sessions similar to the first ones take place, this is, the same task, the same interveners (child with ASD and researcher) but without the robot. The next step is to switch one of the interveners, i.e., the researcher trades places with a known person, for instance a student from the same classroom. Afterwards, the experiment takes place with the child with ASD and an unknown person. It is also intended the context variation, i.e., the experiments take place in the playground. To evaluate the generalized skills, the professionals must fill out the form handed to them. It is intended that the parents have an active role in this proceeding. This way they must evaluate their children's work, conducting the experiment at home without the robot and the activity filmed. They should also answer the questionnaire handed to them at the end of the experiments.

In all the proposed activities, the robot will have a role of mediator/positive reinforcement. On the one hand, it is a mediator because it allows maintaining the child engaged in the activity; once the task is performed successfully, the child is allowed to manipulate the robot, and then the child must return to the task. Doing this, it is intended to increase the focus time of the child with ASD in the proposed task. On the other hand, the robot presents itself as a positive reinforcement because when the task is executed successfully, the child with ASD can manipulate the robot.

There are three activities to perform: 1) gesture to perform an order, 2) the introduction of the notion of quantity, 3) the introduction of the concept of color.

\section{1) Gesture to place an order}

The goal of this activity is to promote the interaction between the child with ASD and an intervener (researcher, professionals, parents or another child with or without ASD). Each child must use a gesture to ask the ball, being the robot mediator/positive reinforcement for this activity.

\section{2) Concept of quantity}

The goal of this activity is to introduce the quantity concept, where the robot tries to encourage this learning. Again, the robot has the role of mediator/positive reinforcement. Each child must throw the number of balls asked towards the intervener. In the case the child with ASD attains success in the performance of the activity, he/she child is rewarded with the robot - positive reinforcement.

\section{3) Color awareness}

The goal of this activity is to introduce the color concept, namely the blue, red, yellow and green colors, where the robot tries also to encourage this learning. Thus, the robot has the role of mediator/positive reinforcement. Each child must throw the ball of the asked color towards the intervener, as well as identifying the color showed by the intervener. In the case the child attains success in the performance of the activity, he/she is rewarded with the robot - positive reinforcement.

\section{Activities Analysis}

As a way to quantify the behavioral analysis of the children, it was necessary to pre-define performance indicators. This would be observed during the interactions of the child with ASD and the robot. Since all the experiments are filmed, it is possible to observe these indicators. These indicators may be divided in three categories: 1) reaction to the robot; 2) action; and 3) object investment.

\section{1) Reaction to the robot}

a. Ignores the robot.

b. Demonstrates specific motor manifestations, for example: stereotypies.

c. Fixation in some detail.

\section{2) Action (behaviors started by free will)}

a. Indicates intention of motor action through the manipulation of the robot.

b. Answers the task.

\section{3) Investments in the subject}

a. Time of interaction around the exploration/manipulation of the robot.

All the indicators mentioned above are counted according to the number of occurrences, except the last indicator which refers to the time of occurrence. After the statistical analysis, it is possible to build the graph of the evolution of performed behaviors of the child with ASD.

\section{Target Group}

The work developed involves 14 children diagnosed with ASD, with ages between 6 and 16 years old, and it is taking place in two schools with different levels of education (primary and secondary schools). These schools belong to the group of schools Aver-o-Mar, in the north Portugal.

The sample is heterogenic in terms of age, gender, verbal language, mental retardation, color awareness and concept of quantity (Table I).

This way, and with the help of professionals and therapists it was necessary to plan each activity, taking into account the needs of each children with ASD. However, after the completion of six experiments, it was possible to observe that the motivation for the task was not the same for each child; the activities complexity allowed by the Lego Mindstorms NXT robot was below the skills possessed by some children. It was necessary to adjust the study, selecting the target children and specify the activity for each. 
TABLE I.

ChaRATIZATION OF THE SAMPLE

\begin{tabular}{|c|c|c|c|c|c|}
\hline Age & Gender & $\begin{array}{c}\text { Verbal } \\
\text { Language }\end{array}$ & $\begin{array}{c}\text { Mental } \\
\text { impairment }\end{array}$ & $\begin{array}{c}\text { Color } \\
\text { awareness }\end{array}$ & $\begin{array}{c}\text { Concept } \\
\text { of } \\
\text { quantity }\end{array}$ \\
\hline $\begin{array}{l}\frac{42,86 \%}{6 \text { to } 8} \\
\text { years } \\
\text { old; } \\
42,86 \% \\
10-13 \\
\text { years } \\
\text { old; } \\
14,29 \% \\
15 \text { to } 16 \\
\text { years } \\
\text { old }\end{array}$ & $\begin{array}{l}\frac{14,29 \%}{\text { female; }} \\
\frac{85,71 \%}{\text { male }}\end{array}$ & $\begin{array}{l}\frac{42,86 \%}{\text { do not }} \\
\text { possess } \\
\text { verbal } \\
\text { language; } \\
\\
\frac{57,14 \%}{\text { possess }} \\
\text { verbal } \\
\text { language }\end{array}$ & $\begin{array}{c}\frac{14,29 \%}{\text { possess }} \\
\text { mental } \\
\text { impairment } \\
\frac{85,71 \%}{\text { not possess }} \text { do } \\
\text { mental } \\
\text { retardation }\end{array}$ & $\begin{array}{l}50 \% \text { is not } \\
\text { aware of } \\
\text { colors and } \\
\text { the other } \\
50 \% \text { is } \\
\text { aware of } \\
\text { colors }\end{array}$ & 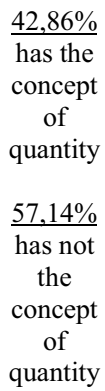 \\
\hline
\end{tabular}

\section{PRELIMINARY RESULTS}

This work is about to move forward to generalization phase. Until this moment tasks were defined and pre-test and the training of skills was performed. The generalization phase is the most important because it allows evaluating whether the skills were acquired or not. For this, the experiments are performed in different contexts and with different interveners.

In parallel with the experiments, preliminary video analysis was performed as well. As an example, Fig. 2 displays the number of times the child responded to the task. This graph shows that initially the child participated in the task. However, in experiment 3 he did not show any interest.

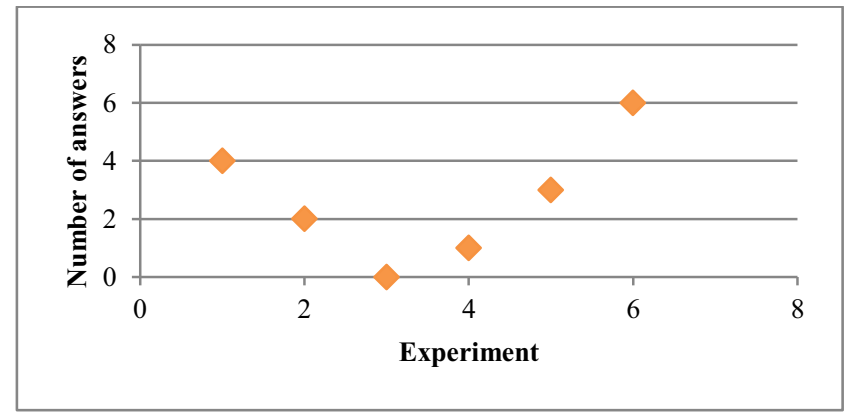

Figure 2. Number of occurrences - responses to the activity.

The responses to the task progressively increased until experiment 6 , which was the last experiment performed until now. This progressive increase may indicate a proportional growth in the interest for the robot by the child with ASD. In the initial stages the robot was activated by the researcher, this means that the child could not manipulate it, while in the last phases the child with ASD was able to manipulate freely the robotic platform.

\section{FINAL COMMENTS}

At this point of the work it is possible to highlight some of the main aspects observed. The management of experiments for all children was complex; hence there was the necessity to reduce the sample. This way, it is possible for the researcher to know them better, therefore adapting the experiments to every single child. A suggestion is to have several small samples along the development of the project. Another important aspect is the effectiveness of the robot's application in intervention. The way each child accepts the robot in the activity is different, since there are different levels of motivation and interest. However, it is impossible to find a pattern which enables the prediction of whether the robot will be a promoter of interactions or it will not bring significant changes to children's behaviors.

In the future work a familiarization phase will be included, where the children can freely explore the robot, reducing anxiety levels and making the robot more attractive.

\section{ACKNOWLEDGMENT}

The authors are grateful to teachers and students of the primary and secondary schools of Aver-o-Mar and their parents for their participation in the project. The authors are also grateful to the Portuguese Foundation for funding through the R\&D project RIPD/ADA/109407/2009.

\section{REFERENCES}

[1] M. First, A. Frances e H. Pincus, DSM-IV-TR - Manual de diagnóstico e estática das perturbações mentais, $4^{\mathrm{a}}$ edição ed., Arlington: American Psychiatric Association, 2002.

[2] C. E. Marques, Perturbações do espectro do autismo, Coimbra: Quarteto 2000

[3] K. Dautenhahn, "Design issues on interactive environments for children with autism," em Proc 3rd Intl Conf Disability, Virtual Reality \& Assoc. Tech, Alghero, Italy, 2000.

[4] S. Costa, F. Soares, C. Santos, M. J. Ferreira, F. Moreira, A. P. Pereira F. Cunha, "An approach to promote social and communication behaviours in children with autism spectrum disorders: robot based intervention," em RO-MAN 20th IEEE International Symposium on Robot and Human Interactive Communication, Atlanta, USA, 2011.

[5] R. Jordan, Educação de crianças e jovens com autismo, Lisboa Institucional, Ed, 2000

[6] H. Barbosa, "Análise do recurso a novas tecnologias no ensino de autistas," Porto, 2009

[7] S. Ozonoff e S. J. Rogers, Perturbações do espectro do autismo: Perspectivas da investigação actual, $1^{\text {a }}$ Edição ed., Lisboa: Climepsi, 2003.

[8] I. Ferreira, "Uma criança com perturbação do espectro do autismo - um estudo de caso," Castelo Branco, 2011

[9] P. C. Silva, C. Eira, J. Pombo, A. P. Silva, L. C. Silva, F. Martins, G. Santos, P. Bravo e P. Roncon, "Programa Clínico para o tratamento das perturbações da relação e da comunicação, baseado no Modelo D.I.R.,' Análise Psicológica, vol. 1 (XXI), pp. 31-39, 2003.

[10] D. J. Ricks e M. B. Colton, "Trends and considerations in robot-assisted autism therapy," em IEEE International Conference on Robotics and Automation, Alaska, USA, 2010.

[11] I. Iacono, H. Lehmann, P. Marti, B. Robins e K. Dautenhahn, "Robots as social mediators for children with autism - A preliminary analysis comparing two different robotic platforms," em Development and Learning (ICDL), IEEE International Conference on, 2011.

[12] H. Kozima, Y. Yasuda e C. Nakagawa, "Social interaction facilitated by a minimally-designed robot: Findings from longitudinal therapeutic practices for autistic children," em RO-MAN 16th IEEE International Conference on Robot \& Human Interactive Communication, Jeju, Korea, 2007.

[13] E. Ferrari, B. Robins e K. Dautenhahn, ""Does it work?" A framework to evaluate the effectiveness of a robotic toy for children with special needs," em RO-MAN 19th IEEE International Symposium on Robot and Human Interactive Communication, Viareggio, Italy, 2010. 